\title{
CONTROL OVER THE DISCRETION POWERS OF THE COMMISSION FOR CONDUCTION OF THE PROCEDURE IN CASE OF APPLYING ART.70 FROM THE PUBLIC PROCUREMENT ACT
}

\author{
S. Subev* \\ National Military University «Vasil Levski», Veliko Tarnovo, Bulgaria
}

\begin{abstract}
Under research are the powers of the commission for considering, assessing and classifying the bids for admission or rejection the justification of the participant under the hypotheses of art. 70 from the Public procurement Act (PPA)
\end{abstract}

Key words: public procurements, commission, discretion powers, justification.

According to the provisions of art.70 from the Public procurement Act, when the bid of a participant contains proposal with figures, which is subject of assessment and it is with more than $20 \%$ more favorable than the average value of the proposals of the other participants under the same index for assessment, the commission should require from this participant a detailed written justification for the way it has been formed. The commission shall determine a reasonable term for submission of the justification, which may not be less than three working days following the receipt of the request for that. The Commission may admit the written justification and may not propose the bid for elimination, when there are specified objective circumstances, connected with:

1. Original solution for realization of the public procurement;

2. The proposed technical solution;

3. The existence of extremely favorable conditions for the participant;

4. Economy during realization of the public procurement;

5. Receipt of state aid.

When the participant does not submit within the (specified) term the written justification or if the commission judges that the pointed circumstances are not objective, the commission shall propose the participant to be eliminated from the procedure.

\footnotetext{
*Correspondence to: Sabin Ivanov Subev, National Military University "Vasil Levski», Veliko Tarnovo, Bulgaria, Tel: +359 8884499 57, subev@abv.bg
}

Some of these provisions are imperative:

It should be required a written justification upon existence of the above-mentioned prerequisite as this action is not within the judgment of the commission.

The comparison shall be made in relation to the average value of the other bids as the rule shall not apply when only two participants have reached the level "assessment" for impossibility to be formed average value.

The provision applies also regarding an index, subject to independent assessment according to the assessment methodology. The rules of art.70 from PPA appear inapplicable for assessment of individual elements of the index for assessment or as regards the price of individual units, which is not subject of independent assessment.

In the rest part the rules of Art. 70 are dispositive. Within the powers of the commission for conduction of the procedure is to judge whether to admit or not the justification of the participant, filed within the term.

The decisions of the commission for conduction of the procedure are not subject of individual appeal, because it has no right to eliminate participants/ it has right to raise proposals to the Contracting authority and the latter in its decision might agree with the proposal of the commission and to eliminate a participant, for whom the commission has considered that the circumstances, pointed in 
the justification are not objective or they are not relevant to the five hypotheses under Art. 70, para 2 from PPA.

If the contracting authority does not accept the proposal of the commission, it has the power under Art. 36a from PPA-prior to issuance of its decision for classification of the participants and selection of contractor to check the contents of the protocols, drawn by the commission, for thier conformity with the requirements of the law and the preiminary announced conditions of the public procurement. If some violations in the work of the commission would be found, which can be eliminated without causing termination of the procedure, the Contracting authority shall give written instructions for their elimination within 5 days following the submission of the respective protocol.

As seen from the provision of art. 36a from PPA, the control is only for conformity with the law - the Contracting authority has no right to interfere in the discretion powers of the commission for conduction of the procedure.

If the Contracting authority agrees with the motives in the protocol of the commission, it shall issue a decision for classification of the participants and selection of contractor, in which has to be pointed also the eliminated participants and the motives for their elimination. According to art. 11, para 1 from PPA the above-mentioned decision appears administrative act, subject of an ex-post control for conformity with the law before the Commission for protection of competition.

Administrative act, issued under the conditions of discretion appears always subject of judicial review for conformity with the law, except when this review is explicitly excluded by a law. The opportunity for assessment, provided by the law should always be used within the frameworks of the law and in pursuance of its purpose. The departure from this particular rule leads to misuse of powers and the violation of the requirements for exertion of the discretion makes the act to be not in conformity with the purpose of law, which appears grounds for cancellation under Art. 146, item 5 from the Administrative procedure Code (APC). In that context is also the provision of Art. 169 from APC, according to which in case of appellation of administrative act, issued within discretion of powers, the court shall verify whether the administrative authority has had such discretion of powers and has it observed the requirement for conformity with the law of the administrative acts. By the above legislative decision the choice of the administrative authority is statutory regulated by Art. 4, para 2 and Art. 6 from APC. 3Therefore if the court has found that the authority has had discretion powers, it has to also check the observance of this regulation. This means that the court has to assess whether by the option, chosen from the authority, may be reached the purpose, for which the law has empowered it to issue the act - Art, 4, para 2, if the purpose is reached, whether it has been possible a decision, less weighty/oppressive for third parties- Art. 6, para 2 and 3 and if such decision did not existhas it existed a decision, realizable with less public funds (resources, efforts and time) Art. 6, para 4. If at least one of these rules has been violated, the act should be considered as being in controversy with the purpose of the law - Art. 146, item 5. The lack of motives in a decision of the Contracting authority (respectively in the protocol from the work of the commission for conduction of the procedure) concerning the issue why it has been chosen one of some possible decisions in conformity with the law, as well as noncollection and non-discussion of the objections and explanations of the interested parties, which concern directly the issue to be solved by the administrative act, appears essential violations of the administrative-procedure rules and appear grounds for cancellation of the act. (1)

The provision of Art. 70, para 2 has a dispositive nature as considering the phrase, used by the legislator -"it may" and the question whether the assessment of the commission to propose a participant for elimination or not ought to be subject of expost control, appears discussible. The commission for protection of competition is a specialized state body, which by a special law is empowered to ensure the statutory realization of the procedures on assignment of the public procurements and it rules only on the conformity of the procedure with the law, not on its expedience/appropriateness. The court, besides its powers to check the administrative acts for their conformity with the law, in certain cases makes a check-up whether the administrative authority has not exceeded the frameworks of its discretion powers and whether it has or has not exerted its right of power, exceeding its assessments in controversy with the purposes, for which it has been assigned to it. If is considered that the existence or lack of circumstances under Art. 70 , para 2 from PPA is a matter of conformity with the law and not a matter of appropriateness, the CPC has to also make the 
check-up of the five hypotheses, specified in para 2, which are given alternatively, not cumulatively. During this check-up an assessment has to be made whether the commission of Contracting authority has mandatorily requested detailed written justification and resp. whether it has stated motives and moreover- whether this commission has correctly admitted this particular justification for objective or not.

According to the continuous case law of the Commission for protection of competition (CPC) and the Supreme administrative court (SAC) the assessment on the objectivity of the submitted written justification is made depending on the appropriateness. In many judgments the court confirms the statement of the CPC that the right of the competition commission to admit or to reject written justification, submitted by the participant, falls within the limits of its discretion powers.(2) According to the case law of the court might be drawn the conclusion that upon the checkup of the written justification it has to be judged whether the facts, pointed in it, are objective and whether they meet some of the circumstances, envisaged in Art. 70, para 2 from PPA. These activities of the commission have to be mandatorily entered into a respective protocol and to be duly motivated.(3) Considering the above-stated it might be drawn a conclusion that upon submission of a written justification the participant has to prove that the more favorable bid is due to a particular, not to all objective circumstances, envisaged in Art. 70, para 2 from PPA. It is obvious from the case law that the procedure on justifying of the more favorable bid assumes submission of detailed written justification for the way of its forming, without being necessary to be enclosed particular evidence. This does not impede the participant to enclose evidence, if he deems this necessary. (Special) power of the commission on competition, which is generally envisaged in the provision of art. 68, para 11 from PPA, is to require evidence for the data in the bid. Its exertion is left to its own independent discretion.(4) In view of the above-mentioned may be drawn the conclusion, that the judgment for the existence of some of the circumstances under Art. 70, para 2 from PPA is made for each individual case and after analysis of the whole factual background. In the general case in the justification ought to be stated reasons, which have relation to the forming of the respective bid and prove that the latter is in conformity with the goals and principles of the law, envisaged in art. 1 and 2 from PPA. For example, according to the case law, the economy of a certain decision may be justified with factors, different by their nature, which are relevant to the subject of the particular public procurement. Here fall the calculation of a minimum profit by the participant, use of own resources (quarries/pits, asphalt bases, service centers, production, warehouse and commercial premises), existence of economical and highly-effective modern equipment, qualified personnel, high commercial discounts because of good reputation and long-lasting relations with the suppliers.

The assessment of the commission under art.34 from PPA to admit or not the justification of the participant appears assessment for the appropriateness, but according to the court, its discretion powers are limited in two directions:

- in the written justification to be pointed objective circumstances,

- these circumstances to be connected and respectively to establish the existence of one of the hypotheses, pointed in the norm under the conditions of alternativeness, as the като supporting body shall be obliged to specify which circumstances, stated in the discussed written justification it considers as being objective and within which one of the five hypotheses of art. 70, para 2 from PPA they fall.

The Supreme administrative court supports the statement, that if the commission for conduction of the procedure has not specified which circumstances from those, stated in the written justification, (it) has considered as objective and within which of the five hypotheses under art. 70, para 2 fall these circumstances, its decision shall appear illegal because of being not motivated. In their acts both the Commission for protection of competition (CPC) and the Supreme administrative court have stressed that the commission should enter into its protocol its analytical arguments why it has reached one or another conclusion upon admission or rejection of justification.

\section{REFERENCES}

1. Judgment № 4128 of 29.03.2010 of SAC, panel of five members under adm. case № $1255 / 2010$

2. Judgment of CPC №216/2011, confirmed with Judgment of SAC №7090/2011

3. Decision of CPC №1303/2010, confirmed by Judgment of SAC №15987/2010

4. Decision of CPC №229/2011, confirmed by Judgment of SAC № 5504/2011 
SUBEV S. 